
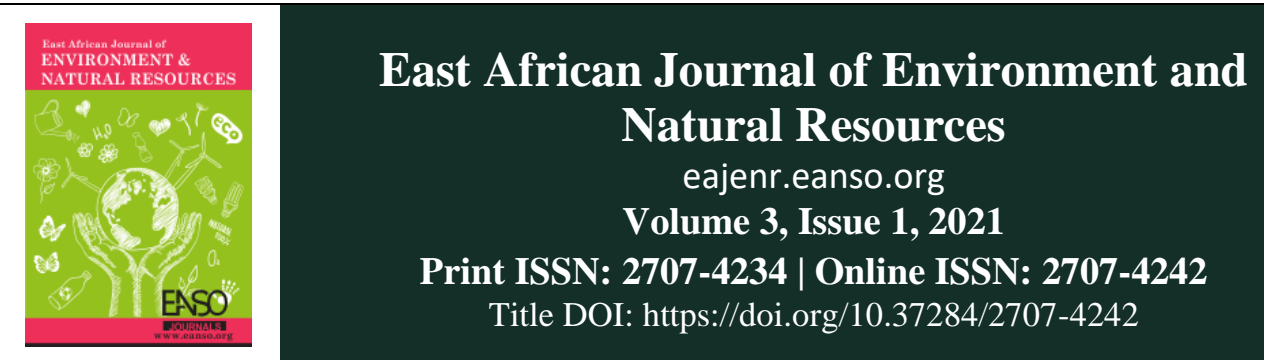

Original Article

\title{
Perceptions of Natural Resources Use in Rwanda - A Partial Proportional Odds Model.
}

\author{
Jean François Régis Nisengwe ${ }^{1 *}$, Adam Willcox, $P h D^{1} \&$ Liem Tran, PhD ${ }^{2}$ \\ ${ }^{1}$ University of Tennessee Institute of Agriculture (UTIA), Smith International Center, 2640 Morgan Circle Drive, Knoxville, TN \\ 37996 USA. \\ ${ }^{2}$ The University of Tennessee Knoxville (UTK); 306 Burchfiel Geography Bldg. Knoxville, TN 37996-0925. \\ *Author for Correspondence ORCID ID: https://orcid.org/0000-0002-4273-1659; Email: jnisengw@ vols.utk.edu.
}

Article DOI: https://doi.org/10.37284/eajenr.3.1.412

\section{Date Published: ABSTRACT}

16 September 2021

The scarcity of natural resources is a challenge in Rwanda. Although Rwanda has improved water supplies, projections show a further increase in water demand.

Keywords: Particularly, agriculture continues to place further demands on water resources through intensification and industrialization. Similarly, although the dependence on

Perceptions, biomass for cooking has improved over the past two decades in Rwanda, the ratio Natural Resource is still high and is projected to increase. Unfortunately, the heavy dependence on Consumption,

Charcoal, biomass is damaging to the environment in general, forests in particular. As the consumption of water and charcoal increases, it is important to study how people

Water, consumption of natural resources are more likely to conserve them as they can see

Rwanda,

Partial how much they are consuming. This study investigated perceptions of water and charcoal consumption among farmers in northern Rwanda. A survey was used to collect data from 323 farmers involved in a poultry development project in the

Proportional

Odds Model. district of Musanze, northern Rwanda. A Partial Proportional Odds Model (PPOM) was used to analyse the effect of different factors on the perception of natural resource consumption. Results indicate that the perception of charcoal consumption was associated with three variables: living in the urban section of the district, the amount of feed consumed by chicken, and elevation at which the coop is located. Results from this study can improve how food security projects are implemented by incorporating people's perceptions of their consumption of natural resources.

\section{APA CITATION}

Nisengwe, J. F. R., Willcox, A., \& Tran, L. (2021). Perceptions of Natural Resources Use in Rwanda - A Partial Proportional Odds Model. East African Journal of Environment and Natural Resources, 3(1), 145-160. https://doi.org/10.37284/eajenr .3 .1 .412

145 | This work is licensed under a Creative Commons Attribution 4.0 International License. 


\section{CHICAGO CITATION}

Nisengwe, Jean François Régis, Adam Willcox and Liem Tran. 2021. "Perceptions of Natural Resources Use in Rwanda - A Partial Proportional Odds Model". East African Journal of Environment and Natural Resources 3 (1), 145-160. https://doi.org/10.37284/eajenr.3.1.412.

\section{HARVARD CITATION}

Nisengwe, J. F. R., Willcox, A., \& Tran, L. (2021) "Ecological Responses of Macroinvertebrates to an In-Stream Ecosystem Restoration Technique in a Tropical Stream in Eastern Uganda”, East African Journal of Environment and Natural Resources, 3(1), pp. 145-160. doi: 10.37284/eajenr.3.1.412.

\section{IEEE CITATION}

J. F. R. Nisengwe., A. Willcox., \& L. Tran, "Perceptions of Natural Resources Use in Rwanda - A Partial Proportional Odds Model”, EAJENR, vol. 3, no. 1, pp. 145-160, Sep 2021.

\section{MLA CITATION}

Nisengwe, Jean François Régis, Adam Willcox and Liem Tran. "Perceptions of Natural Resources Use in Rwanda - A Partial Proportional Odds Model”. East African Journal of Environment and Natural Resources, Vol. 3, no. 1, Sep 2021, pp. 145-160, doi:10.37284/eajenr.3.1.412.

\section{INTRODUCTION}

The scarcity of natural resources continues to be a challenge in Rwanda. Concerning water, the literature indicates that by 2010 , daily per capita consumption of water was around 13 litres per day in Rwanda; this quantity is lower than the envisaged standard consumption of 20 litres (MININFRA, 2013). According to the World Health Organization (WHO, 2013), 20 litres per capita is the quantity needed to take care of basic hygiene needs and basic food hygiene. Rwanda is lagging behind because of the scarcity of water resources. More recently, Nkurunziza (2016) reported that the average water consumption per capita in the northern part of Rwanda is estimated to be between 4.7 and 12.3 litres per day. Additionally, the study reported that $21.58 \%$ of respondents fetched water more than 1000 meters from their residence and that $38.91 \%$ of respondents took more than 30 minutes to collect water. Although Rwanda has taken laudable steps to improve water supply and access, projections continue to show a further increase in water demand (MININFRA, 2013; UNEP, 2010). The projected increase in water demand is based on factors such as population growth, urbanization, rapid economic development, and decreasing mortality rate (MINIRENA, 2012). Additionally, agriculture continues to place further demands on water resources, particularly, intensification and industrialization (NISR, 2019). Agriculture consumes more water than any other sector in Rwanda (over 65\%) (Bizuhoraho et al., 2018). Although much of water consumption in agriculture comes from irrigation activities, data suggest that livestock development, especially cattle, consumes water resources to an appreciable degree (MINIRENA, 2012).

Similar to water, energy resources are an additional challenge as rural households in Rwanda rely on biomass consumption (i.e. charcoal and firewood), mainly for cooking. Slander and Hendriksen (2012) reported that as of 2011, approximately $86 \%$ of primary energy in Rwanda came from biomass, mainly in the form of wood; wood is either used directly as fuel $(57 \%)$ or converted into charcoal (23\%) together with smaller amounts of crop residues and peat $(6 \%)$. Although the dependence on biomass has improved over the past two decades (from $95 \%$ to $86 \%$ ), the ratio is still high (Bimenyimana et al., 2018). In Rwanda, the use of charcoal in rural areas is likely to increase due to continued urbanization and an increasing population (Marge, 2009). Specifically, one of the challenges facing Rwanda's energy sector is to produce and consume biomass-based energy without harming the environment (Munyaneza et al., 2016). Unfortunately, the heavy dependence on biomass is intrinsically damaging to the 
environment in general, particularly forest resources (Bimenyimana et al., 2018; Mazimpaka, 2014).

As the demand for both water and charcoal continue to increase, understanding farmers' perceptions of these resources and their consumption are important. Research is starting to indicate that people who accurately understand their resource consumption patterns may be more likely to conserve them since they are aware of how much they are consuming as they can personally assess how changes in their behaviour affect resource consumption. For example, in a study done by Fan et al. (2014) in the Wei River Basin in China, it was reported that household water consumption can be easily reduced when people understand their consumption. A good understanding of farmer's perception of water availability and use is crucial as perception can affect their decisions and behaviours such as crop choice and water allocation (Kuil et al., 2018). To date, there exist no studies in the literature that show farmers' perceptions of both water and charcoal consumption in Rwanda. Until we understand farmers' perceptions of natural resource consumption, we cannot make sound policies to improve farmers' decision-making and ultimately their behaviours. Nor can we improve outreach and education programs that are likely to lead to more sustainable consumption patterns of natural resources.

This study investigated the factors that affect natural resource consumption among farmers in Musanze district, northern Rwanda. To achieve this, the study attempts to answer the following question: What factors influence perceptions of water and charcoal consumption among farmers in Musanze district, northern Rwanda? To answer this question, data were collected from poultry farmers who were taking part in the food security project: Tworore Inkoko, Twunguke (TI) - Kinyarwanda for Let's raise chicken and make a profit. This project leverages public-private partnerships among USAID/Rwanda; a US-based foundation, African
Sustainable Agriculture Project (ASAP); a Rwandan animal feed company, Zamura Feeds Ltd.; and a US land-grant institution, University of Tennessee Institute of Agriculture (UTIA). As part of the project, enrolled farmers receive 100 chicks per six-week cycle and are encouraged to keep at least three of the chickens for consumption at the end of each production cycle. Additionally, the project offers training and support to farmers so they can be successful in their broiler chicken production. The enrolled farmers use charcoal as a source of fuel for chicken brooding and use water to tend to chickens.

\section{MATERIALS AND METHODS}

\section{Study Area and Data}

To investigate the factors that affect farmers' perceptions of natural resource use, we surveyed farmers between September and December 2019. With the Institutional Review Board (IRB) approval (IRB number: UTK IRB-17-03708-XM), we collected data from poultry farmers living in Musanze district, northern Rwanda. Musanze district has three sub-levels of administrative units, in order of largest to smallest: Sectors, Cells, and Villages. In this research, we collected data from three sectors where the TI project was running: Kinigi, Muhoza, Gataragara (Figure 1). Kinigi and Gataraga sectors are rural sectors while Muhoza is considered an urban/peri-urban sector.

We used a three-stage random sampling approach by administrative unit (cell, village, household). The number of surveys was chosen to be proportional to the larger administrative unit's population. Thus, the survey responses were proportional to the actual populations within each administrative unit to allow for the greatest possibility of accurate representation. This design relied on the TI project data collection design for farmers' recruitment, household survey, and project evaluation. 
Figure 1: Study area (Musanze district, northern Rwanda)

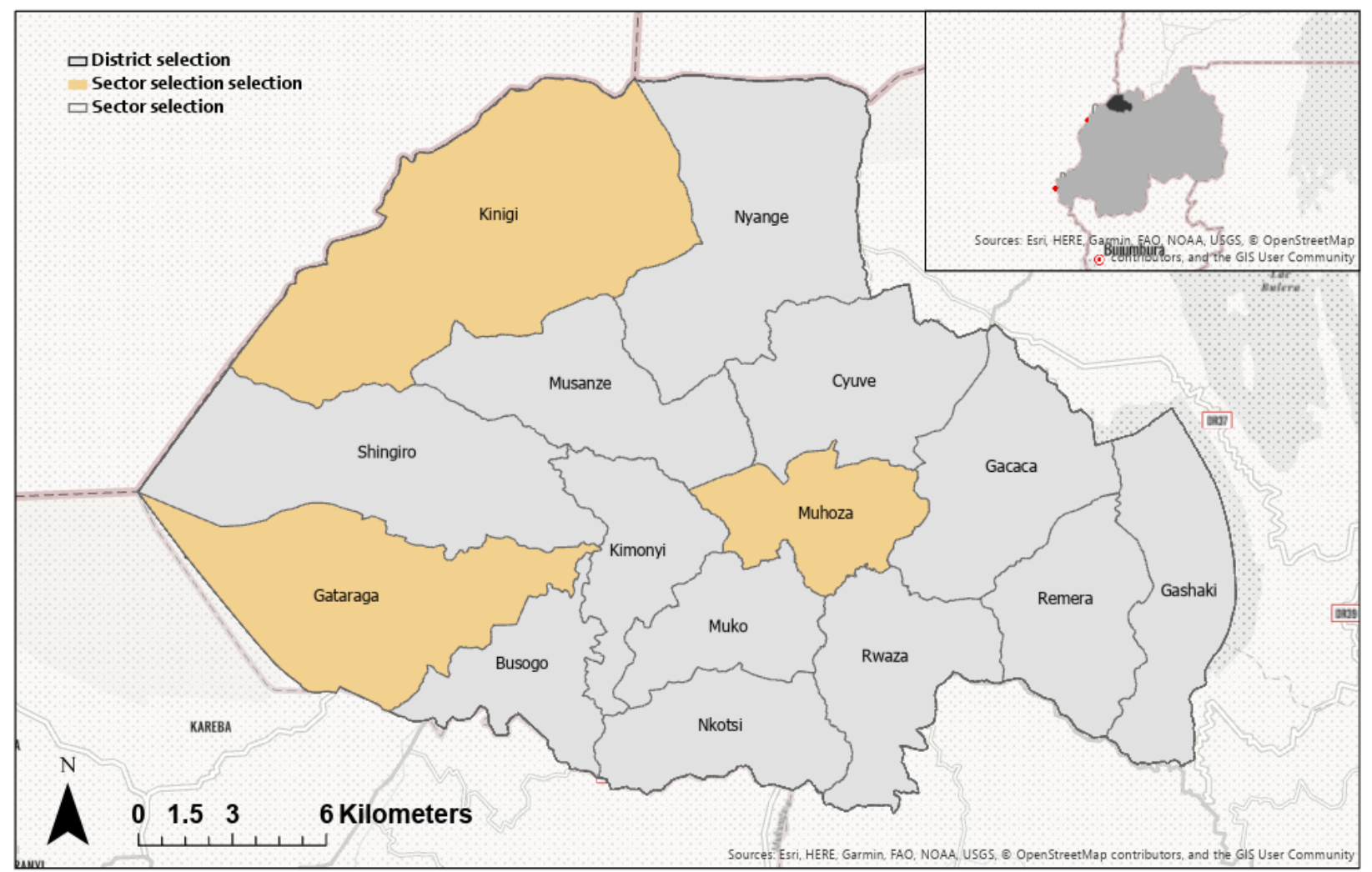

Data was collected as part of the monitoring and evaluation data collection that the TI project conducts every year. A questionnaire was used to collect data and was administered using tablets and the DroidSurvey (2.9.3) software, the data collection tool provided by HarvestYourData ${ }^{1}$ services. To ensure the quality of the collected data, enumerators were trained by teams from the University of Tennessee Institute of Agriculture (UTIA) and the TI project before the survey. The questionnaire was first tested during a pilot phase to minimize errors and biases that could result from the way the questionnaire was designed. The survey was piloted 15 times, with nine female and six male poultry farmers. The pilot was useful in improving the questionnaire; for example, the questions on Food Insecurity Experience Scale (FIES) were

1 www.harvestyourdata.com; address: 3 Kaitawa Road York Bay Lower Hutt New Zealand

2 The Food Insecurity Experience Scale by Food and Agriculture Organization (FAO). While the original scale of reduced from 8 to 6 based on the context in Rwanda.

The instrument was short enough to not be a burden on the respondent and to allow the enumerators to conduct multiple interviews in a day. The length of time for one respondent to complete the survey ranged from 10 to 15 minutes.

The dependent variables in the study were the perception of water use and perception of charcoal use (see Table 2 in results). Independent variables in the study were age, gender, urban, food insecurity index (FIES) ${ }^{2}$, education, feed consumed, and elevation, and Ubudehe (a socio-economic status variable) (see Table 3 in results). There are four categories of Ubudehe in Rwanda, ranging from 1 to 4 . Category 1 includes families who do not own

the index uses 8 questions related to food insecurity, the current study used a modified-scale of 6 questions. The higher the number the more food insecure.

148 | This work is licensed under a Creative Commons Attribution 4.0 International License. 
a house and can hardly afford basic needs. Category 2 includes households that have a dwelling of their own or can rent one but rarely get full-time jobs. Category 3 includes households who have a job and farmers who go beyond subsistence farming to produce a surplus that can be sold. The latter also includes those with small and medium enterprises who can employ dozens of people. Category 4 includes those who own large-scale businesses, individuals working with international organizations and industries as well as public servants (GoR, 2015).

Data on elevation were calculated based on the geographical coordinates of every farmer while data on the feed consumed was based on the reported data from the TI project data report. The Food Insecurity Experience Scale (FIES) was adopted from the TI project measure of food security. This measure was also based on the scale developed by (Ballard \& Cafiero, 2013). This scale $^{3}$ has 8 questions but has been modified based on local context and pilot testing by the TI project to have 6 questions from 0 (food secure) to 6 (food insecure).

\section{Data Analysis, Model Specification, and Estimation Procedures}

\section{Proportional Odds Model (POM)}

In the context of the study, perception is assessed by evaluating whether farmers feel that their use or consumption of natural resources has changed since they joined the project and to what extent they feel that their resource use has changed. The following measures were used to assess the perception of water consumption: Our household uses much less water than it did before the project $(Y=1)$; Our household uses less water than it did before the project $(Y=2)$; Our household uses the same amount of water as it did before the project $(Y=3)$; Our household uses more water than it did before

3 See Table 2: Questions that compose FIES and explanations of the intended meanings on page 14 of (Ballard \& Cafiero, 2013) the project $(Y=4)$, and Our household uses much more water than it did before the project $(Y=5)$. Similarly, the same measure has been used for the perception of charcoal use: Our household uses much less charcoal than it did before the project ( $Y$ =1); Our household uses less charcoal than it did before the project $(Y=2)$; Our household uses the same amount of charcoal as it did before the project $(Y=3)$; Our household uses more charcoal than it did before the project $(Y=4)$; Our household uses much more charcoal than it did before the project $(Y=5)$. These five outcomes constituted the 5category dependent variable, $\mathrm{Y}$, and the number of perception levels (denoted as $\mathbf{J}$ in this study) is 5 . When a response variable is categorical and ordered, the ordinal logistic regression is the most appropriate model (Anderson, 1984).

One of the commonly used ordinal models is the proportional odds model (POM) (Dolgun \& Saracbasi, 2014). The proportional odds model can be intuitively thought of as being based on odds ratios formed over a series of successive incremental cut-points. Each cut-point-specific estimate is calculated using all observations in the sample, but at a different dichotomization of the outcome (Scott et al., 1997).

The common assumption in an ordinal logistic regression is that the relationship between each pair of outcome groups is the same. Thus, for each independent variable, its effect on the probability of being at or beyond any category is assumed to be the same within the model; thus, the slope estimate provides a summary of each independent variable's relationship to the outcome across all cut-points. This constraint is known as the proportional odds assumption or the parallel regression assumption (O’Connell \& Liu, 2011). Thus, ordinal logistic regression assumes that the coefficients that describe the relationship between the lowest level of natural resource perception $(Y=1)$ versus all higher

149 | This work is licensed under a Creative Commons Attribution 4.0 International License. 
levels of perceptions $(Y=2,3,4$, and 5) are the same as those that describe the relationship between the next lowest level of natural resource perception $(Y$ $=2)$ and all higher levels $(Y=3,4$, and 5), etc.

The perception measure Yi can be estimated as follows:

$Y_{i}=X_{i} \beta+\varepsilon$

where $\beta$ is the regression coefficients for $\mathrm{X}, \varepsilon$ is the identically and independently distributed error term.

Let $m_{\mathrm{k}}$ be the thresholds (cutoffs) for natural resource perception (water or charcoal), $\mathrm{k}=1,2, \ldots$, $\mathrm{J}-1$. Note that level $\mathrm{k}=1$ represents the minimum threshold, much less water or charcoal. The different values of $\mathrm{Y}$ are as follows:

$\mathrm{Y}=1$ (much less water or charcoal): if $\mathrm{Y} \leq m_{1}$

$\mathrm{Y}=2$ (less water or charcoal): if $m_{1} \leq \mathrm{Y} \leq m_{2}$

$\mathrm{Y}=3$ (same amount): if $m_{2} \leq \mathrm{Y} \leq m_{3}$

$\mathrm{Y}=4$ (more water or charcoal) if $m_{3} \leq \mathrm{Y} \leq m_{4}$

$\mathrm{Y}=5$ (much more water or charcoal): if $\mathrm{Y}>m_{4}$

Since $\mathbf{J}$ is the number of perception levels, then the probability of perception level (j) for a given variable (i) can be written as:

$P\left(Y_{i}>j\right)=P_{i j}=\frac{e^{\left(\alpha_{j}+X_{i} \beta\right)}}{1+e^{\left(\alpha_{j}+X_{i} \beta\right)}}$

where $\beta$ is the regression coefficients for $X$ (difference in the log odds of having perception level $\mathrm{j}$ vs. other $\mathrm{j}-1$ perception levels), $\mathrm{j}$ is the intercept for $\mathrm{j}^{\text {th }}$ logit. It is to be noted that the values of the coefficients for all $\mathrm{J}$ perception levels will be the same because of the proportional odds assumption. However, this assumption could be violated in many cases. For example, if we consider natural resource perception, ordered logit models assume that the independent variables have the same effect on the occurrence of much less, less, same, more, and much more water or charcoal, thereby resulting in only one set of coefficients for all the influential factors. For the analysis of the perception of natural resource consumption, it is unclear whether the distances between different perception levels are equal or not.

When running any of the ordinal logistic regression models, it is recommended to check whether the assumption of proportionality is satisfied by each independent variable. To check the proportionality assumption, a Likelihood ratio (LR) test can be performed. However, the limitation with the LR test is that it is an omnibus test; as such, it does not show whether the proportionality assumption is violated for all independent variables or only for some (Dolgun \& Saracbasi, 2014). Consequently, a valid method to test the proportionality assumption both in an omnibus and individual manner is preferred.

Brant's Wald test statistic has been proposed to check the proportional odds assumption for all independent variables or only for some (Brant, 1990). The current study used the Brant test to check the proportionality assumption. For example, results from the Brant test conducted on the perception of charcoal consumption (Table 1) showed that the model violated the proportionality assumption overall (Omnibus) and one variable in particular (FIES). Both the proportional odds model and the Brant test were run using the MASS framework by Venables \& Ripley (2002) in the R software (R Core Team, 2013). 
Table 1: Brant test to check the proportionality assumption on the perception of charcoal consumption in Musanze district, Rwanda, 2019

\begin{tabular}{llll}
\hline Test for & X2 & df & probability \\
\hline Omnibus & 39.31 & 24 & $0.03^{* *}$ \\
age & 2.73 & 3 & 0.44 \\
gender & 2.02 & 3 & 0.57 \\
urban & 4.51 & 3 & 0.21 \\
Ubudehe & 5.85 & 3 & 0.12 \\
FIES & 19.16 & 3 & $0.00^{* * *}$ \\
education & 3.36 & 3 & 0.34 \\
feed_consumed & 4.73 & 3 & 0.19 \\
elevation & 3.72 & 3 & 0.29
\end{tabular}

Brant test: Perception of charcoal consumption; Number of observations: 323 ; **Significant at $\mathrm{p}<.05$; $* * *$ Significant at $\mathrm{p}<.001$.

\section{Partial Proportional Odds Model (PPOM)}

The results from the proportional odds model are valid only when the proportionality assumption holds. To test the validity of the model, the Brant test was run on the results from the model, and the test results revealed that the proportionality assumption was violated. When the proportionality assumption holds, one can move forward with the proportional odds model. Conversely, when the test reveals that the assumption does not hold, two options are possible: non-proportional odds model (NPOM) and partial proportional odds model (PPOM). Both models relax the constraints of the proportional odds assumption by allowing all the coefficients to vary in the case of NPOM or allowing some coefficients to vary in the case of PPOM (Dolgun \& Saracbasi, 2014; O’Connell \& Liu, 2011).

Since our model revealed that not all variables violated the assumption (see Error! Reference source not found.), the partial proportional odds model seemed to be more appropriate. The partial proportional odds model considers the ordinal nature of the dependent variable while at the same time allowing for possible violation of the proportional odds assumption from explanatory variables (Soon, 2010).
According to the partial proportional odds model, the probability of perception level (j) for a given variable (i) can be written as:

$P\left(Y_{i}>j\right)=P_{i j}=\frac{e^{\left(\alpha_{j}+X_{i} \beta_{j}\right)}}{1+e^{\left(\alpha_{j}+X_{i} \beta_{j}\right)}}$

In the PPOM model shown in Eq (3), it is possible for the variables, say, $X_{1}$ and $X_{2}$ to satisfy the proportional odds assumption and therefore the coefficients for $X_{1}$ and $X_{2}$ are the same for all levels of the dependent variable. On the other hand, some other variables such as $X_{3}$ may not meet the proportional odds assumption, and hence coefficients for $X_{3}\left(\beta_{3 j}\right)$ are free to vary for different levels of the dependent variable. This scenario can be written as (Sasidharan \& Menéndez, 2014):

$P_{i j}=\frac{e^{\left(\alpha_{j}+X_{1 i} \beta_{1}+X_{2 i} \beta_{2}+X_{3 i} \beta_{3 j}\right)}}{1+e^{\left(\alpha_{j}+X_{1 i} \beta_{1}+X_{2 i} \beta_{2}+X_{3 i} \beta_{3 j}\right)}}$

In the case of our data, this model allowed the perception of natural resources as the dependent variable while allowing the violation of the proportional odds from specific explanatory variables. Failing to relax the model like this can result in incorrect models and results (Ananth \& Kleinbaum, 1997). The vector generalized linear and additive model (VGLM/VGAM) framework 
within the R software, developed by Yee (2010), was used to address this problem by fitting the data using the partial proportional odds model.

\section{RESULTS}

\section{Descriptive Statistics}

On average, respondents perceive that their consumption of charcoal has increased since the project started $($ mean $=3.6 ; \mathrm{SD}=0.9$, on a point scale of 1 to 5). Additionally, results indicate that on average respondents perceive their water consumption has highly increased (mean $=4.27$; SD $=0.59$ on a point scale of 1 to 5$)$.
The majority of respondents $(64 \%)$ reported that they perceive that they are using more water than before the project started. Less than $2 \%$ of respondents feel that the amount of water they use has decreased. Comparatively, only 3\% of respondents, feel that the amount of water did not change. Regarding charcoal, the majority of respondents $(66 \%)$ perceive that they are using more charcoal than before the project. Conversely, $16 \%$ of respondents feel that they are using less charcoal than before the project whereas less than $2 \%$ feel that they using even much less charcoal. Comparatively, only $4 \%$ of respondents feel that they are using the same amount of charcoal as before the project.

Table 2: Summary of responses from farmers' $(n=323)$ perception of natural resource consumption after starting a new poultry project in Musanze district, Rwanda, 2019.

\begin{tabular}{lllll}
\hline & Responses & Meaning & f & \% \\
\hline & 1 & Much less water & 1 & 0.31 \\
& 2 & Less water & 3 & 0.93 \\
Perceptions of water consumption & 3 & Same amount & 9 & 2.79 \\
& 4 & More water & 206 & 63.78 \\
& 5 & Much more water & 104 & 32.20 \\
& & Total & $\mathbf{3 2 3}$ & $\mathbf{1 0 0 . 0 0}$ \\
\hline Perceptions of charcoal consumption & 1 & Much less charcoal & 6 & 1.86 \\
& 2 & Less charcoal & 54 & 16.72 \\
& 3 & Same amount & 14 & 4.33 \\
& 4 & More charcoal & 212 & 65.63 \\
& 5 & Much more charcoal & 37 & 11.46 \\
& & Total & $\mathbf{3 2 3}$ & $\mathbf{1 0 0 . 0 0}$ \\
\hline
\end{tabular}

Overall, the mean age for respondents was 40 years $(\mathrm{SD}=11)$. Among all respondents, 50 percent were women. On average, respondents are in category 2 of socioeconomic status (Ubudehe). Category 2 represents those who have a dwelling of their own or can rent one but rarely get full-time jobs. The average food insecurity index (FIES) is 2.45 . The higher the index the more food insecure the respondent. The highest degree of education attained was university while the mean elevation for all respondents was 2,1336 meters $(\mathrm{SD}=242)$. On average, $596.15 \mathrm{kgs}$ of feed was consumed by chickens ( $\mathrm{SD}=160$ ). There are differences in the values across the three sectors (see Table 3). For example, chickens in Gataraga consume more feed $(652.21 \mathrm{kgs} /$ cycle) than chickens in other sectors. Muhoza sector is at the lowest elevation compared to other sectors. 
Table 3: Summary of descriptive statistics of responses from farmers' $(n=323)$ perception of natural resource consumption after starting a new poultry project in Musanze district, Rwanda, 2019 organized by sector

\begin{tabular}{|c|c|c|c|c|c|}
\hline \multirow{2}{*}{\multicolumn{6}{|c|}{ 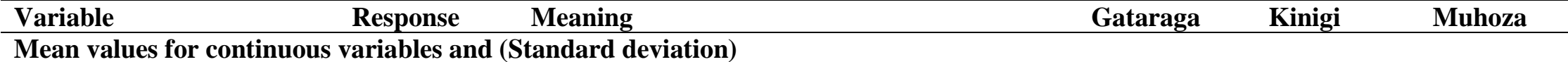 }} \\
\hline & & & & & \\
\hline Age & \multicolumn{2}{|c|}{ Mean age (years) } & $41.25(10)$ & $38.51(10)$ & $40.95(12)$ \\
\hline Feed consumed & \multicolumn{2}{|c|}{ Mean quantity of feed consumed by chickens per cycle (kgs/cycle) } & $652.21(158)$ & $509.93(130)$ & $588.37(154)$ \\
\hline Elevation & \multicolumn{2}{|c|}{ Mean elevation at which the coop is located $(\mathrm{m})$} & $2152.40(112)$ & $2440.93(17)$ & $1825.61(44)$ \\
\hline \multicolumn{6}{|c|}{ Count of categorical variables } \\
\hline \multirow{9}{*}{ Education } & 1 & None & 0 & 3 & 1 \\
\hline & 2 & Some primary & 41 & 25 & 9 \\
\hline & 3 & Completed primary (1-6) & 40 & 22 & 19 \\
\hline & 4 & Vocational school & 0 & 1 & 0 \\
\hline & 5 & Some secondary & 36 & 28 & 25 \\
\hline & 6 & Completed secondary (7-12) & 23 & 6 & 28 \\
\hline & 7 & Some university & 1 & 0 & 3 \\
\hline & 8 & Completed university & 4 & 1 & 7 \\
\hline & 9 & Graduate school & 0 & 0 & 0 \\
\hline \multirow[t]{2}{*}{ Gender } & 0 & Male & 87 & 42 & 32 \\
\hline & 1 & Female & 58 & 44 & 60 \\
\hline \multirow{4}{*}{ Ubudehe } & 1 & & 17 & 6 & 6 \\
\hline & 2 & $1=$ lowest income, $4=$ highest income & 68 & 31 & 53 \\
\hline & 3 & & 60 & 49 & 32 \\
\hline & 4 & & 0 & 0 & 0 \\
\hline \multirow[t]{7}{*}{ FIES (Food insecurity index) } & 0 & & 57 & 40 & 27 \\
\hline & 1 & & 14 & 4 & 4 \\
\hline & 2 & & 14 & 10 & 2 \\
\hline & 3 & $0=$ food secure, $6=$ food insecure & 13 & 6 & 7 \\
\hline & 4 & & 10 & 7 & 21 \\
\hline & 5 & & 15 & 4 & 16 \\
\hline & 6 & & 22 & 15 & 15 \\
\hline
\end{tabular}




\section{Factors Influencing the Perception of Charcoal} Consumption

Proportional Odds Model (POM) Results: Results show that three variables are associated with the perception of charcoal consumption: urban, feed_consumed, and elevation. According to the results (Table 4), farmers who live in the urban section of the district are more likely to feel that their consumption of charcoal has increased since the project started. Regarding feed_consumed, results reveal that farmers whose chickens consume more quantity of feed tend to perceive that they use higher quantities of charcoal than before the project started. Lastly, for elevation, farmers who live in higher altitudes are more likely to perceive that they are using larger quantities of charcoal than before the project started.

Table 4: Results from the proportional odds model for the perception of charcoal consumption of farmers in Musanze district, Rwanda, 2019

\begin{tabular}{lllll}
\hline & Value & Std. Error & t value & p-value \\
\hline age & -0.00597 & 0.011507 & -0.51902 & 0.604 \\
gender & 0.268637 & 0.243764 & 1.10204 & 0.270 \\
urban & 2.108462 & 0.306663 & 6.875506 & $0.000^{* * *}$ \\
ubudehe & -0.22403 & 0.186912 & -1.19859 & 0.231 \\
FIES & 0.023348 & 0.050215 & 0.464971 & 0.642 \\
education & 0.011791 & 0.076024 & 0.155091 & 0.877 \\
feed_consumed & 0.003628 & 0.000701 & 5.174671 & $0.000^{* * *}$ \\
elevation & 0.00364 & 0.000332 & 10.97536 & $0.000^{* * *}$ \\
$\mathbf{1 | 2}$ & 5.765135 & 0.046543 & 123.8678 & 0.000 \\
$\mathbf{2} \mid \mathbf{3}$ & 8.384792 & 0.376832 & 22.25077 & 0.000 \\
$\mathbf{3 | 4}$ & 8.680189 & 0.380791 & 22.79513 & 0.000 \\
$\mathbf{4 | \mathbf { 5 }}$ & 12.2641 & 0.448451 & 27.34771 & 0.000 \\
\hline
\end{tabular}

Dependent variable: Perception of charcoal consumption; Number of observations: $323 ; * *$ Significant at $p<.05 ; * * *$ Significant at $p<.001$.

Mathematically, the intercept $1 \mid 2$ corresponds to logit $[\mathrm{P}(\mathrm{Y} \leq 1)]$. It can be interpreted as the log of odds of perceiving that one is using 'Much less charcoal' versus perceiving that one is using 'Less charcoal'. Similarly, the intercept $2 \mid 3$ corresponds to logit $[\mathrm{P}(\mathrm{Y} \leq 2)]$. It can be interpreted as the $\log$ of odds of perceiving that one is using 'Less charcoal' versus perceiving that one is using 'The same amount'. Other intercepts follow the same logic.

Partial Proportional Odds Model: With the partial proportional odds model, the effects of the variables that meet the proportionality assumption are interpreted the same way as in the proportional odds model. For other variables, examining the pattern of coefficients reveals insights that would otherwise be difficult to detect in the case of proportional odds model (Williams, 2006). In contrast, effects on variables that were allowed to vary (urban, feed consumed, and elevation) will be interpreted a little differently.

As was the case with the proportional odds model, the results from the partial proportional odds model (Table 5) revealed that the three statistically significant factors that influence the perception of charcoal consumption are the same as in the previous model: Living in the urban section of the district (urban), the quantity of feed consumed by chickens (feed consumed), and elevation at which the coop is built (elevation). However, the partial proportional odds model revealed further where the greatest effects were. Thus, for urban, farmers who live in the rural section of the district were more likely to perceive that they were using higher 
quantities of charcoal than their peers who live in rural sections in general, but the greatest effect was to move farmers away from the lowest value of perception. Likewise, the overall effect of the quantity of feed consumed by chicken (feed consumed) was that farmers are more likely to perceive that they are using more quantities of charcoal. However, the greatest effect of feed consumed was to move farmers from the middle values of perception. Lastly, farmers who live in higher altitudes were more likely to feel that they are using more charcoal in general, but the greatest effect of elevation was to push farmers away from the lowest category of perception.

Table 5: Results from Partial Proportional Odds Model for farmers' perception of charcoal consumption in Musanze district, Rwanda, 2019

\begin{tabular}{lllll}
\hline & Estimate & Std. Error & $\mathbf{z}$ value & $\operatorname{Pr}(>|\mathbf{z}|)$ \\
\hline (Intercept):1 & -17.6601 & 10.12737 & -1.743802 & 0.081 \\
(Intercept):2 & -11.0666 & 2.915444 & -3.7958526 & 0.000 \\
(Intercept):3 & -11.5605 & 2.734276 & -4.2280032 & 0.000 \\
(Intercept):4 & -4.97831 & 3.683351 & -1.3515722 & 0.177 \\
age & -0.00479 & 0.011934 & -0.4011429 & 0.688 \\
gender & 0.273532 & 0.24509 & 1.1160458 & 0.264 \\
urban:1 & 4.152054 & 1.883775 & 2.2041136 & $0.028 * *$ \\
urban:2 & 2.373586 & 0.600366 & 3.9535678 & $0.000^{* * *}$ \\
urban:3 & 2.472806 & 0.564081 & 4.3837747 & $0.000^{* * *}$ \\
urban:4 & 0.962363 & 0.744 & 1.2934986 & 0.196 \\
ubudehe & -0.22988 & 0.191062 & -1.2031484 & 0.229 \\
FIES & 0.024458 & 0.051367 & 0.4761376 & 0.634 \\
education & 0.014992 & 0.077478 & 0.1934972 & 0.847 \\
feed_consumed:1 & 0.004031 & 0.00353 & 1.1417349 & 0.254 \\
feed_consumed:2 & 0.00472 & 0.001144 & 4.1244593 & $0.000^{* * *}$ \\
feed_consumed:3 & 0.00462 & 0.001047 & 4.411435 & $0.000^{* * *}$ \\
feed_consumed:4 & 0.001877 & 0.001161 & 1.6159062 & 0.106 \\
elevation:1 & 0.009051 & 0.004466 & 2.0264308 & 0.043 \\
elevation:2 & 0.004574 & 0.001139 & 4.0157628 & $0.000^{* * *}$ \\
elevation:3 & 0.004678 & 0.001063 & 4.4002925 & $0.000^{* * *}$ \\
elevation:4 & 0.000907 & 0.001462 & 0.6199299 & 0.535 \\
\hline
\end{tabular}

Dependent variable: Perception of charcoal consumption; Number of observations: $323 ; * *$ Significant at $p<.05 ; * * *$ Significant at $p<.001$.

\section{Factors Influencing the Perception of Water Consumption}

Proportional Odds Model (POM) results of the perception of water consumption (Table 6) indicate that only the food insecurity index (FIES) was found significant. This suggests that farmers who are more food insecure than their peers are more likely to feel that they are using more quantity of water than what they used before the project started. 
East African Journal of Environment and Natural Resources, Volume 3, Issue 1, 2021

Article DOI: https://doi.org/10.37284/eajenr.3.1.412

Table 6: Results from Proportional Odds Model for farmers' perception of water consumption in Musanze district, Rwanda, 2019

\begin{tabular}{lllll}
\hline & Value & Std. Error & t value & p value \\
\hline age & 0.006934 & 0.012291 & 0.564185 & 0.573 \\
gender & 0.239364 & 0.243963 & 0.98115 & 0.327 \\
urban & -0.32759 & 0.27977 & -1.17091 & 0.242 \\
ubudehe & -0.02505 & 0.201882 & -0.12409 & 0.901 \\
FIES & 0.266318 & 0.05435 & 4.900095 & $0.000 * * *$ \\
education & -0.00741 & 0.076372 & -0.09696 & 0.923 \\
feed_consumed & -0.00044 & 0.000754 & -0.58189 & 0.561 \\
elevation & -0.00013 & 0.000362 & -0.35637 & 0.722 \\
$\mathbf{1 | 2}$ & -5.62378 & 0.05337 & -105.373 & 0.000 \\
$\mathbf{2} \mid \mathbf{3}$ & -4.22859 & 0.203619 & -20.7671 & 0.000 \\
$\mathbf{3 | 4}$ & -3.03083 & 0.353134 & -8.58267 & 0.000 \\
$\mathbf{4 | 5}$ & 1.10616 & 0.436373 & 2.534895 & 0.011 \\
\hline
\end{tabular}

Dependent variable: Perception of water consumption; Number of observations: $323 ; * *$ Significant at $p<.05 ; * * *$ Significant at $p<.001$.

As was the case for perception of charcoal, mathematically, the intercept $1 \mid 2$ corresponds to logit $[\mathrm{P}(\mathrm{Y} \leq 1)]$, which can be interpreted as the $\log$ of odds of perceiving that one is using 'Much less water' versus perceiving that one is using 'Less water'. Likewise, the intercept $2 \mid 3$ corresponds to logit $[\mathrm{P}(\mathrm{Y} \leq 2)]$. It can be interpreted as the $\log$ of odds of perceiving that one is using 'Less water' versus perceiving that one is using 'The same amount' and so on.

\section{Partial Proportional Odds Model (PPOM)}

Since effects on the variable (FIES) were allowed to vary in the partial proportional odds model, they will be interpreted a little differently. As was the case in the proportional odds model, results from the partial proportional odds model (Table 7) indicate that farmers who are food insecure were more likely to perceive that they were using higher quantities of charcoal than their peers who were relatively less food insecure. However, the partial proportional odds model further revealed that the greatest effect was to move farmers away from the highest value of perception.

Table 7: Results from Partial Proportional Odds Model for farmers perception of water consumption in Musanze district, Rwanda, 2019

\begin{tabular}{lllll}
\hline & Estimate & Std. Error & z value & $\operatorname{Pr}(>|\mathbf{z}|)$ \\
\hline (Intercept):1 & 5.927383 & 2.818447 & 2.103067 & 0.035 \\
(Intercept):2 & 4.197107 & 2.537541 & 1.654006 & 0.098 \\
(Intercept):3 & 4.197107 & 2.537541 & 1.654006 & 0.098 \\
(Intercept):4 & -1.36608 & 2.487258 & -0.54923 & 0.583 \\
age & 0.007069 & 0.012569 & 0.562386 & 0.574 \\
gender & 0.249605 & 0.254881 & 0.9793 & 0.327 \\
urban & -0.3291 & 0.502439 & -0.65501 & 0.512 \\
ubudehe & -0.009 & 0.200127 & -0.04497 & 0.964 \\
FIES:1 & 0.041362 & 0.40216 & 0.102849 & 0.918 \\
FIES:2 & 0.219562 & 0.220535 & 0.995587 & 0.319 \\
FIES:3 & -0.21671 & 0.129558 & -1.67269 & 0.094
\end{tabular}

156 This work is licensed under a Creative Commons Attribution 4.0 International License. 
East African Journal of Environment and Natural Resources, Volume 3, Issue 1, 2021

Article DOI: https://doi.org/10.37284/eajenr.3.1.412

\begin{tabular}{lllll}
\hline & Estimate & Std. Error & z value & $\operatorname{Pr}(>|\mathbf{z}|)$ \\
\hline FIES:4 & 0.334559 & 0.057237 & 5.84514 & $0.000^{* * *}$ \\
education & -0.00827 & 0.079373 & -0.10414 & 0.917 \\
feed_consumed & -0.00045 & 0.000818 & -0.55003 & 0.582 \\
elevation & -0.00013 & 0.000952 & -0.14009 & 0.889 \\
\hline
\end{tabular}

Dependent variable: Perception of water consumption; Number of observations: 323 ; **Significant at $p<.05 ; * * *$ Significant at $p<.001$.

\section{DISCUSSION}

As results revealed, urban, feed consumed, and elevation variables were associated with the perception of charcoal consumption. Results from the analysis (Table 4 and Table 5) showed that farmers who live in the urban section of the district are more likely to feel that their consumption of charcoal has increased since the project started. As the majority of farmers who live in the urban section of the district normally use less charcoal than those living in rural sections, it may not be a big surprise for those living in the urban area to feel that their consumption has increased. In contrast, farmers who live in rural sections of the district are used to using charcoal in their everyday life and they may not feel that their use has changed.

Regarding feed consumed, results reveal that farmers whose chickens consume more quantity of feed tend to perceive that they use higher quantities of charcoal than before the project started. Since charcoal is used for heating in the brooding activity, it is possible that chickens that consume more feed require more heating as they need energy to convert the feed into meat. Literature suggests that temperature is an important factor in broiler feed conversion (Aviagen, 2011).

Lastly, farmers who live in higher altitudes are more likely to perceive that they are using larger quantities of charcoal than before the project started. This perception may be due to a higher demand for more charcoal to keep the chickens warm in lower temperatures typical of higher altitudes. Therefore, farmers may feel that they are using higher quantities of charcoal since the project started.
According to the results of the perception of water consumption (Table 6 and Table 7), the food insecurity index (FIES) was the only variable that was found significant. This suggests that farmers who are more food insecure than their peers are more likely to feel that they are using more quantity of water than what they used before the project started. Since farmers who are food insecure may not have easy access to water resources, it may be easy for them to feel the burden to use water resources to tend to chickens. As a result, they may feel that they are using more water resources than they used to use before the project started.

Although both water and charcoal are natural resources, they were not found to be associated with the same factors. Age, gender, education, and Ubudehe were not found to have any significant relationship with either the perception of water consumption or the perception of charcoal consumption.

\section{CONCLUSIONS}

Since this study investigated perceptions of natural resource consumption, it is worth acknowledging that these are perceptions of resource consumption, not exact measures of resource consumption. Therefore, overestimation or underestimation of natural resource consumption can occur. Examples of overestimation and underestimation of water consumption (Attari, 2014; Fan et al., 2014) or Energy consumption (Attari et al., 2010) exist. Consequently, although results indicated that the consumption of natural resources has increased, the conclusion on whether actual consumption has increased will require further investigation. Future studies can further assess whether the actual

$157 \mid$ This work is licensed under a Creative Commons Attribution 4.0 International License. 
consumption of natural resources has changed and the factors that influence that change.

Nonetheless, although perceptions of natural resource consumption from respondents may differ from the actual natural resources use, they are still important because they can inform better management of resources (Fernández-Llamazares et al., 2016). Furthermore, although the majority of farmers feel that their consumption of resources has increased since the project started, it is crucial to note that there might be many factors that may have contributed to the increased consumption of resources; some may be related to the project while others may not be related to the project.

As research suggests, people who accurately understand their resource consumption patterns may be more likely to conserve them since they are aware of how much they are consuming (Fan et al., 2014). To encourage behaviour change towards sustainable consumption of natural resources, we need to start by assessing people's perceptions of their consumption of natural resources.

The findings of this study suggest that food security projects might increase the likelihood of farmers to perceive that they consume more natural resources as a result of taking part in these projects. Thus, it is recommended that the management of natural resources be integrated into the design of food security projects such as the TI project.

\section{ACKNOWLEDGMENTS}

We would like to thank the faculty at the University of Tennessee, Knoxville (UTK), and the Smith Center for International Agriculture staff at the University of Tennessee Institute of Agriculture (UTIA) whose suggestions, comments, and questions improved the clarity and quality of this paper. We acknowledge the help from the enumerators who collected the data used in this study and the reviewers as well as the editor(s) who made the review and the publication process smooth. We also extend our gratitude to farmers who participated in this study. All human subjects research protocols for this study were approved by the UT Institutional Review Board: UTK IRB-1703708-XM.

\section{Funding Information}

This manuscript has been possible by the generous support from the Smith Center for International Sustainable Agriculture at the University of Tennessee Institute of Agriculture. This study was conducted with the financial support of USAID/Rwanda and the African Sustainable Agriculture Project (ASAP) Foundation as a Global Development Alliance, Tworore Inkoko, Twunguke (Let's raise chickens for profit) project (USAID Cooperative Agreement No.: AID-696-A-1700006) with a sub-award to Zamura Feeds Limited, Ruhengeri, Rwanda.

\section{REFERENCES}

Ananth, C. V., \& Kleinbaum, D. G. (1997). Regression models for ordinal responses: A review of methods and applications. International Journal of Epidemiology, 26(6), 1323-1333. https://doi.org/10.1093/ije/26.6.1323

Anderson, J. A. (1984). Regression and Ordered Categorical Variables. Journal of the Royal Statistical Society, 46(1), 1-30. https://doi.org/10.2307/2346101

Attari, S. Z. (2014). Perceptions of water use. Proceedings of the National Academy of Sciences of the United States of America, 111(14), 5129-5134. https://doi.org/10.1073/pnas.1316402111

Attari, S. Z., DeKay, M. L., Davidson, C. I., \& De Bruin, W. B. (2010). Public perceptions of energy consumption and savings. Proceedings of the National Academy of Sciences of the United States of America, 107(37), 16054-16059. https://doi.org/10.1073/pnas.1001509107

Aviagen. (2011). Arbor Acres Service Bulletin Optimizing Broiler Feed Conversion Ratio. 7. Retrieved from http://en.aviagen.com/ 
Ballard Kepple, A. W., \& Cafiero, C. (2013). Technical Paper. Rome, FAO., T. J. (2013). The food insecurity experience scale: Developing a global standard for monitoring hunger worldwide. Technical Paper. (October), 1-58.

Bimenyimana, S., Asemota, G. N. O., \& Li, L. (2018). The state of the power sector in Rwanda: A progressive sector with ambitious targets. Frontiers in Energy Research, 6(July). https://doi.org/10.3389/fenrg.2018.00068

Bizuhoraho, T., Icyimpaye, G., \& Nadia, B. E.-S. (2018). Water Demand Management as a Solution to Water Resources Challenges in Rwanda. International Journal of Science and Research (IJSR), 9(1), 52-70.

Brant, R. (1990). Assessing Proportionality in the Proportional Odds Model for Ordinal Logistic Regression Author (s): Rollin Brant Published by: International Biometric Society Stable URL: https://www.jstor.org/stable/2532457 REFERENCES Linked references are available. Biometrics, 46(4), 1171-1178.

Dolgun, A., \& Saracbasi, O. (2014). Assessing proportionality assumption in the adjacent category logistic regression model. Statistics and Its Interface, 7(2), 275-295. https://doi.org/10.4310/SII.2014.v7.n2.a12

Fan, L., Wang, F., Liu, G., Yang, X., \& Qin, W. (2014). Public perception of water consumption and its effects on water conservation behavior. Water (Switzerland), 6(6), 1771-1784. https://doi.org/10.3390/w6061771

Fernández-Llamazares, Á., Díaz-Reviriego, I., Guèze, M., Cabeza, M., Pyhälä, A., \& ReyesGarcía, V. (2016). Local perceptions as a guide for the sustainable management of natural resources: Empirical evidence from a smallscale society in Bolivian Amazonia. Ecology and Society, 21(1), 1-26. https://doi.org/10.5751/ES08092-210102

GoR. (2015). Community-led Ubudehe categorisation kicks off. Retrieved April 13, 2020, from Republic of Rwanda website: http://www.gov.rw/news_detail/?tx_ttnews\%5B tt_news $\% 5 \mathrm{D}=1054 \& \mathrm{cHash}=\mathrm{a} 315 \mathrm{a} 8 \mathrm{~b} 0054 \mathrm{e} 76 \mathrm{f} 9$ c699f05ce24d3eb8

Government of Rwanda (NISR, M. of E. and M. of L. and F. (2019). Rwanda Natural Capital Accounts - Water. World Bank, (March), 86. Retrieved from https://www.wavespartnership.org/sites/waves/f iles/kc/RW_NCA_Land_Account_March__201 8_IV__1_.pdf

Kuil, L., Evans, T., McCord, P. F., Salinas, J. L., \& Blöschl, G. (2018). Exploring the Influence of Smallholders' Perceptions Regarding Water Availability on Crop Choice and Water Allocation Through Socio-Hydrological Modeling. Water Resources Research, 54(4), 2580-2604.

https://doi.org/10.1002/2017WR021420

Marge. (2009). Biomass Energy Strategy ( Best), Rwanda. European Union Energy Initiative, (June).

Mazimpaka, E. (2014). Woodfuel in Rwanda: Impact on energy, poverty, environment and policy instruments analysis. International Journal of Renewable Energy Development, 3(1), 21-32. https://doi.org/10.14710/ijred.3.1.21-32

MININFRA. (2013, June). Water and Sanitation Sector Strategic Plan. Republic of Rwanda. Retrieved from http://www.minecofin.gov.rw/fileadmin/templat es/documents/sector_strategic_plan/Water_and _Sanitation_SSP_June_2013.pdf

MINIRENA. (2012). Water resources management sub-sector strategic plan (2011-2015). Republic of Rwanda, (September), 1-50.

Munyaneza, J., Wakeel, M., \& Chen, B. (2016). Overview of Rwanda Energy Sector: From Energy Shortage to Sufficiency. Energy Procedia, 104, 215-220. https://doi.org/10.1016/j.egypro.2016.12.037

Nkurunziza, F. (2016). Water quality , quantity and accessibility assessment: Volcanoes national park region experience in Rwanda. International 
Journal of Recent Advances in Multidisciplinary Research, 03(07), 1617-1626.

O'Connell, A. A., \& Liu, X. (2011). Model diagnostics for proportional and partial proportional odds models. Journal of Modern Applied Statistical Methods, 10(1), 139-175. https://doi.org/10.22237/jmasm/1304223240

Sasidharan, L., \& Menéndez, M. (2014). Partial proportional odds model - An alternate choice for analyzing pedestrian crash injury severities. Accident Analysis and Prevention, 72, 330-340. https://doi.org/10.1016/j.aap.2014.07.025

Scott, S. C., Goldberg, M. S., \& Mayo, N. E. (1997). Statistical assessment of ordinal outcomes in comparative studies. Journal of Clinical Epidemiology, 50(1), 45-55. https://doi.org/10.1016/S0895-4356(96)00312-5

Slander, K., \& Hendriksen, G. (2012). Establishing a Green Charcoal Value Chain in Rwanda: A feasibility study. The World Bank, 108. Retrieved from https://www.scopus.com/inward/record.uri?eid $=2$-s 2.0 84919786396\&partnerID=40\&md5=cdaf719f3 $6776781970 c 496101745258$

Soon, J. J. (2010). The determinants of students' return intentions: A partial proportional odds model. Journal of Choice Modelling, 3(2), 89$112 . \quad$ https://doi.org/10.1016/S17555345(13)70037-X

UNEP. (2010). Africa water atlas. In United Nations Environment Programme (Division o). https://doi.org/10.1007/s00264-013-1939-9

Venables, W.., \& Ripley, B.. (2002). Tree-Based Methods. In: Modern Applied Statistics with S. Statistics and Computing. https://doi.org/https://doi.org/10.1007/978-0387-21706-2_9

WHO. (2013). Water sanitation hygiene. Retrieved October 8, 2020, from https://www.who.int/water_sanitation_health/e mergencies/qa/emergencies_qa5/en/

Williams, R. (2006). Generalized ordered logit/partial proportional odds models for ordinal dependent variables. Stata Journal, 6(1), 58-82. https://doi.org/10.1177/1536867x0600600104

Yee, T. W. (2010). Journal of Statistical Software The VGAM Package for Categorical Data Analysis. 32(10). Retrieved from http://www.jstatsoft.org/

160 | This work is licensed under a Creative Commons Attribution 4.0 International License. 